Integration involves a trade-off between fertility and status for World War II evacuees

\title{
Lynch, Robert
}

2019-04

Lynch , R , Lummaa , V , Panchanathan , K, Middleton, K, Rotkirch , A, Danielsbacka , M , O'Brien , D \& Loehr , J 2019 , ' Integration involves a trade-off between fertility and status for World War II evacuees ' , Nature Human Behaviour, vol. 3 , no. 4 , pp. 337-345 . https://doi.org/10.1038/s41562-019

http://hdl.handle.net/10138/333664

https://doi.org/10.1038/s41562-019-0542-5

unspecified

acceptedVersion

Downloaded from Helda, University of Helsinki institutional repository.

This is an electronic reprint of the original article.

This reprint may differ from the original in pagination and typographic detail.

Please cite the original version. 


\title{
Integration involves a trade-off between fertility and status for World War II evacuees.
}

\author{
Lynch, Robert ${ }^{1,}$, Lummaa, Virpi ${ }^{1}$, Panchanathan, Karthik ${ }^{2}$, Middleton, Kevin ${ }^{2}$, Rotkirch, \\ Anna $^{3}$, Danielsbacka, Mirkka' ${ }^{1}$, O'Brien, David², and Loehr, J ohn ${ }^{3}$
}

\author{
${ }^{1}$ University of Turku, Turku, Finland \\ 2University of Missouri, Columbia, MO, USA \\ 3University of Helsinki, Helsinki, Finland \\ *rofrly@utu.fi
}

\begin{abstract}
Understanding how refugees integrate into host societies has broad implications for researchers interested in intergroup conflict and governments concerned with promoting social cohesion. Using detailed records tracking the movements and life histories of Finnish evacuees during World War II, we find that evacuees who intermarry are more likely to be educated, work in professional occupations, marry someone higher in social status and remain in the host community. Evacuees who intermarry before the war have fewer children while those who intermarry after the war have more children. These results suggest that integration involves a trade-off between reproduction and status such that evacuees who integrate gain social status while those who maintain stronger bonds with their natal communities have higher fertility. We discuss these results within the framework of social capital, intergroup conflict, and life history theory and suggest how they can inform our understanding of evolutionary adaptations that affect tribalism.
\end{abstract}

\section{Introduction}

Understanding how migration affects the relationship between natal groups and dispersers is crucial for gaining insight into how intraspecies competition and cooperation impact evolution ${ }^{1}$. In mammals dispersal is seen to provide benefits by both reducing inbreeding and offering advantages in mate competition ${ }^{2}$ and overall dispersal is favored whenever the fitness costs of remaining in one's birth area outweigh the costs of migrating ${ }^{3}$. In humans, competition and cooperation between groups has been shown to drive dispersal patterns ${ }^{4}$ which in contemporary societies are frequently characterized by mass exoduses resulting from war, natural disasters or disparate economic opportunities between host and emigrant countries ${ }^{5}$. Although these migrations have enormous impacts on both host and immigrant populations, there is considerable disagreement across disciplines about how these events affect life-history outcomes and overall social cohesion ${ }^{6}$. Various theoretical frameworks have been proposed to understand the underlying causes of cooperation and conflict between individuals and groups. Evolutionary biologists, for example, focus on kinship ${ }^{7}$ and reciprocity ${ }^{8}$, while economists examine markets and externalities ${ }^{9}$ and sociologists and social psychologists tend to be concemed with factors influencing intergroup tolerance and integration ${ }^{10}$. Researchers across disciplines, however, often reference 'social capital' - the norms, networks and transactions marked by reciprocity and trust that enable people to act collectively and are beneficial to the common good ${ }^{11}$ - when seeking to understand the effects of immigration on society (see Supplementary materials: Social Capital) and there is widespread agreement that social capital has important effects on integration and social cohesion ${ }^{12}$.

Although there is a broad consensus that social capital affects relationships within and between groups, there is considerable disagreement about how immigration affects social capital. For instance, the "contact hypothesis", first proposed by G.W. Allport, posits that higher rates of contact with people from different backgrounds will tend to increase tolerance of other groups under specific conditions, such as equal status between the immigrant and host popul ations ${ }^{13}$ (see Supplementary materials: The Contact Hypothesis). In this view, immigration will promote social solidarity and build trust as contact with different types of people with diverse backgrounds increases. Although there is some evidence that increasing the number of positive contacts between host and immigrant popul ations reduces anti-immigrant attitudes in Europe, these attitudes were found to be largely dependent on conditions and context ${ }^{14}$. Alternatively, the "conflict hypothesis" makes the distinction between bonding social capital - the relationships, ties and networks amongst people who share a culture and similar background — and bridging social capital - the connections between groups that transcend cultural difference ${ }^{15}$ (see Supplementary materials: Social Capital). Examples of bonding social capital include the language, dialects, rituals and traditions specific to a certain community, while bridging capital is often characterized by social networks that transcend these differences such as membership in organizations that have people from diverse backgrounds. This viewpoint purports that the increased diversity resulting from 
immigration exacerbates conflict between immigrants and hosts by reducing bridging social capital and increasing bonding social capital (i.e. in-group solidarity) ${ }^{12,16}$. It predicts that the more we are brought into physical proximity with people from another culture or ethnic background, the more westick to our own groups and the less we trust people who are different from us. In short, competition between the immigrant and host popul ations is thought to reduce tolerance and impede integration.

The contact and conflict hypotheses are not mutual ly exclusive, however, and there is considerable evidence that individual characteristics can affect rates of integration. For example, while younger immigrants ${ }^{17}$ and immigrants from higher social classes ${ }^{18}$ are expected to integrate more quickly, lower social classes are expected to: 1) compete more with the host popul ation over resources; 2) form tighter within group social networks and 3) be less likely to integrate ${ }^{19}$. Attitudes of the host population may also affect integration. For example, lower education ${ }^{20}$, rural residence ${ }^{21}$ and the perceived threat and size of theimmigrant population ${ }^{20}$ are known to be some of the best predictors of hostile attitudes towards immigrants. There is al so evidence that the social networks of younger, urban and more educated individual s are more likely to bridge group boundaries whi le the networks of older, rural and less educated individuals are more restricted to their own in-group ${ }^{22}$. Families with more education in Britain are seen to be more upwardly mobile because of their ability to form connections with a more diverse group of people $e^{23}$. An important type of bridging social capital is intermarriage which has been shown to increase empl oyment opportunities, raise income and result in the greater social integration of immigrants. This is often due to both selection effects (i.e. immigrants who are more integrated are al so more likely to intermary) and to positive effects of the marriage on further integration and the generation of additional bridging social capita ${ }^{24}$. Internal migration within a country can al so have effects on both migrants and hosts. Boustan et. al. ${ }^{25}$ found that, al though internal ly displaced migrants in the United States during the Great depression had no effect on overall wages, these migrants did cause many longer term residents to leave and substantial ly reduced the work hours of those who remained. This research suggests that internal migrants can have just as disruptive of an impact on labor markets as immigrants from other countries. Overall, the demographic characteristics of the migrants, competition over resources, and the social networks that connect hosts with migrants are all expected to affect economic outcomes and the rate of integration.

The benefits accrued by one group may come at a cost to another, however, and al though increased bonding within immigrant groups can reduce overall social cohesion and inhibit integration, it may still provide direct benefits to theimmigrant population. In particular, the mere act of moving through space together has been experimentally shown to increase group sol idarity ${ }^{26}$ and stronger within group social bonds have been shown to increase reproductive outcomes in many specie ${ }^{27}$. In addition, evolutionary simul ations have demonstrated that enhanced bonding with in-group members can be adaptive ${ }^{28}$. Kulu et. al. ${ }^{29}$, for example, have shown that, al though the descendants of immigrants to European countries often have fertility rates that are similar to those of the native population in their respective countries, the host society and the mi nority subcul ture both exert strong influences on these birth rates. Sweden, for example, had the lowest fertility variation across ethnic groups and the authors attributed this to low levels of residential segregation and high labor market integration in Nordic countries ${ }^{24}$. Other researchers have argued that the strength of social networks within immigrant and minority populations can affect fertility outcomes ${ }^{30}$. Higher educational achievement - especially amongst femal $\mathrm{e}^{31}$, intergroup marriages ${ }^{29}$, further cultural distance from the host population ${ }^{30,32}$, increased opportunities for social and economic mobility and a desire for acculturation have all been shown to reduce fertility ${ }^{33}$. At the same time, greater access to close $\mathrm{kin}^{34}$, resistance to assimilation and concern with group preservation have been shown to increase reproductive output ${ }^{35}$. Integration can al so entail risks of ostracismfrom one's ingroup and there is good evidence for both parochialism ${ }^{28}$ and mobility traps - the opportunities gained by joining a new group conflict with opportunities for upward mobility within one's former group ${ }^{36}$ — in humans. In this way, developing bridging connections can weaken key social connections and create stress by forcing individuals to deepen their commitment to their new group while cutting off connections with their old communities ${ }^{37}$. Because many anthropol ogists contend that support fromnon-parents is critical to offspring survival ${ }^{38}$ and decisions to reproduce ${ }^{39}$, increasing these bridging social connections may adversely affect reproductive outcomes if they interfere with or repl ace weaker bridging ties.

Despite evidence showing that the demographic characteristics of individuals and populations have important effects on the relationship between immigrants and host populations, it remains unknown how these factors interact to affect both integration and life-history outcomes. Exploring these interactions has been challenging for several reasons. First, accessing longitudi nal datasets that contain the marriage records, reproductive histories, birthplaces, occupations and movements of an entire popul ation across decades is exceptionally rare. Second, it is difficult to anal yze how bonding and bridging social capital affect integration and reproduction when we don't know who would return to their natal community if given the opportunity. This is important because there is evidence showing that groups that are more easily able to return home are less likely to build strong bonding social networks than those whose exit is bl ocked ${ }^{40}$. Finally, we are rarely able to directly compare the integration and life history outcomes of those who chose to return to their natal communities from those who remai ned because they are effectively different populations existing in separate locations.

Here, we use an unusual ly well-documented dataset of the marriages, reproductive histories, movements and occupations of a population of evacuees from Karelia, Finland, during World War II, to test whether integration involves a trade-off 
between status and reproduction by examining the impacts that age at migration, population size, education, social class and ingroup bonding have on marriage, migration patterns and reproductive outcomes. On November 30th, 1939 the Soviet Union invaded Finland which started the Winter War. Four months later, in March of 1940, the southern portion of Finnish Karelia approximately 10 percent of Finnish teritory - was ceded to the Soviet Union and approximately 410,000 individuals (12\% of the population of Finland) had to flee west ${ }^{41}$ (see Figures 1a-c). Although the Finnish government played an important role in organizing the exodus and attempted to keep evacuees from the same towns together (see Supplementary Material s: The Influence of the Finnish Government on the Evacuations) and to distribute them widely and evenly amongst the resident population (seeSupplementary Material s: Evacuations and the Proportion of Migrants to Hosts), the evacuations were frequently chaotic. The evacuees spoke a Karelian dial ect of Finnish. Before urbanization took place in Finland in 1950 s and $1960 \mathrm{~s}^{42}$ this difference was especially notable (For rel ative differences between dial ects of Finni sh ca. 100 years ago, see ${ }^{43}$; Figures 12 and 13) and the Karelian dialect was easily distinguished. In addition to cultural differences, these linguistic differences contributed to Karelians facing discrimination due to their ethnic background (see Supplementary Material s: Prejudices Against Evacuees). Government enforced land sal es to accommodate the evacuees al so fuel ed resentment agai nst Karel ians. A short peace fol lowed until J une of 1941 when Finland joined Germany's attack on the Soviet Union. This resul ted in the Continuation War and three months after it began Finland had recaptured all of the lost territories. For the next three years, fromAugust of 1941 until the spring of 1944, Finland once again controlled the Karelian territories and more than half of the evacuees retumed home. By August of 1944, however, the Soviet Union had recaptured Karelia and those who had returned were once again evacuated; this time their ability to return was permanently bl ocked. This unique historical situation provides a quasi natural experiment which allows us to analyze some of the factors which distinguished the peopl e who remai ned in Western Finland from those who returned home, and presents an extraordinary opportunity to investigate differences in social integration and life history outcomes between these two groups. By comparing the marriages and reproductive histories of the evacuees who returned to Karel ia with those who did not, we are able to assess how natal philopatry - preferences for returning to one's birthplaceaffects later integration and reproduction.

Intermarriage is used to assess social integration (eg. individuals who marry non-Karelian Finns are seen as more socially integrated), while number of offspring is used to assess reproductive outcomes. In this study we ai m to anal yze the impact of bonding and bridging social capital on integration and life history outcomes. We model how decisions to return to Karelia or remain in western Finland impact on how likely evacuees are to intermary and how many children they have in the pre-war and post-war environment. First, we hypothesize that younger immigrants will assi milatemore quickly with a host population than ol der migrants and predict Pla) that younger people will be more likely to marry into the host population after the war. Second, we hypothesize that evacuees who prefer to return to their place of birth will be less likely to integrate and predict P1b) that those who retum to Karelia during the war will be less likely to marry into the host population both before and after the war. Third, we hypothesize that the risks of integration will be partly offset by increased economic opportunities and predict P1c) that evacuees who intermarry will gain social or economic benefits of integration by being more likely to marry someone from a higher social class both before and after the war ends. Fourth, in a test of the 'contact hypothesis' we hypothesize that individual s living in areas with higher population density will have had more interactions with people from different backgrounds, will be better able to transcend regional and cultural differences between groups and will therefore be more likely to integrate. Specifically, we predict Pld) that evacuees who are from areas of high population density in Karelia will be used to interacting with people who are different from them and will be more likely to intermarny both before and after the war. Fifth, in a test of the 'conflict hypothesis' we predict that more educated Karelians will be more capable of transcending group boundaries and will be more wel comed by the host community. Specifically we predict Ple) that more educated evacuees will be will be more likely to intermarry both before and after the war. Final ly, to test the impact of bonding social capital on integration and life history outcomes, we hypothesize that individuals who retum to Karelia and those who marry other Karelians will both reap reproductive benefits by maintaining stronger cultural bonds with their natal community. Specifical ly we predict that P2a) Karelians across all social classes, birth cohorts and occupations who marry other Karelians will have more children than those who marry resident Finns and P2b) Karelians across all social classes, birth cohorts and occupations who return to Karelia during the War will have more children than those who remain in the rest of Finland.

Overall, many of the same factors that increase the probability of integration have a negative effect on fertility. Error bars and raw data for all variables used in this study can be accessed with this interactive app: ht t ps: / / www. hel si nki . $\mathrm{f} \mathrm{i} \mathrm{/} \mathrm{en/} \mathrm{proj} \mathrm{ect} \mathrm{s/} \mathrm{I} \mathrm{ear} \mathrm{ni} \mathrm{ng-} \mathrm{f} \mathrm{r} \mathrm{om} \mathrm{our} \mathrm{-} \mathrm{past} \mathrm{/} \mathrm{dat} \mathrm{a \# s} \mathrm{ect} \mathrm{i} \mathrm{on-} \mathrm{60700.} \mathrm{Wefound} \mathrm{support} \mathrm{for} \mathrm{the} \mathrm{prediction} \mathrm{that}$ younger evacuees (Pla) were more likely to marry into the host population after the war. Evacuees who eventually marry resident Finns after the war are an average of 2.8 years younger at the time of the first evacuation. The mean age of evacuees who intermarny after the war is 21.4 (S.E. + -0.09) but is 24.2 (S.E. + - 0.20) for evacuees who marry other Kare ians. The model predicts that an average (see Methods: Model validity, effects and specifications), unmarried evacuee who is 15 years old in 1939 (at the time of the first evacuation) is predicted to have an $89 \%$ (95\% HDI : 87\%-91\%) probability of eventually marrying a resident Finn which decreases to $48 \%$ (95\% HDI : 43\%-52\%) for an unmarried evacuee who is thirty years old in 
1939. Evacuees who marry another Karelian before the war are al so, perhaps unsurprisingly, more likely to return to Karelia. The model predicts that Karelians who return have an 18\% (95\% HDI : 16\%-20\%) chance of being married to someone from western Finland while those who do not have a 38\% (95\% HDI : 34\%-41\%) chance of being married to someone from western Finland (Plb). At the same time, an average evacuee who marries after the war and remains in western Finland (Plb) is al so more likely to intermarry 68\% (95\% HDI: 65\%-71\%) than someone who returns to Karelia 58\% (95\% HDI: 55\%-62\%).

To test the prediction that evacuees receive social or economic benefits through integration (P1c) we tested whether evacuees who intermarny are more likely to marny someone from a higher social class both before and after the war. If a Karelian marries someone from a higher social class (see Methods: Predictor variables- hypergamy) before the Soviet invasion the model predicts that the probability that their spouse is from western Finland is approximately $26 \%$ (95\% HDI: $24 \%-28 \%$ ) which falls to $22 \%$ (95\% HDI: $20 \%-25 \%$ ) if they marry someone from a lower social class (see Figures 2a and 3). For these pre-war marriages the relationship between hypergamy and intermarriage as well as the overall probability of intermarriage is nearly identical for men and women. After the war ends intermarriage is al so positively associated with marying up. Evacuees who marny someone from a higher social class have a $66 \%(95 \% \mathrm{HDI}$ : 63\%-69\%) chance of marrying into the host population and this falls to $57 \%$ (95\% HDI: 53\%-61\%) if they marry someone from a lower social class (see Figure 3). Although overall, women are predicted to be more likely to intermary after the war - 74\% (95\% HDI: 71\%-77\%) for women vs 50\% (95\% HDI 46\%-54\%) for men - the relationship between hypergamy and intermarriage after the war is driven more by men (see Figure 2a and Supplementary Material s: TableS1). Men are more likely to have a wife who is froma higher social class if they marry into the host population- 55\% (95\% HDI: 51\%-58\%) chance of intermarriage if their wife is from a higher social class and a $45 \%$ chance (95\% HDI: $41 \%-49 \%$ ) if she is froma lower social class vs. women who have a $78 \%$ (95\% HDI: $75 \%-80 \%$ ) chance of intermarying if their husband is from a higher social class and a 70\% (95\% HDI : 66\%-74\%) chance if he is froma lower social class (Figure2-left panel). Although both before and after the war some degree of hypergamy was achieved by evacuees who intermarried regardless of whether they retumed to Karelia, after the war marying up strongly predicts intermarriage for evacuees who remain in westem Finland (see Supplementary Materials: Table S4). For example, a mal e evacuee who remains in western Finland and marries up after the war has a 63\% (95\% HDI: 58\%-67\%) chance of marrying into the host population whereas if this same individual returns to Karelia, their predicted probability of marying up and into the host population falls to $49 \%$ (95\% HDI: $45 \%-53 \%$ ). Therefore, evacuees who remain in western Finland are not only more likely to marry into the host population after the war (P1b), they are al so more likely to marry up when they do (P1c). Final ly there were some basic sex differences between the probability of males and femal es intermamying and returning to Karelia (seeTableS8).

There was no evidence in any of the models that evacuees bom in towns with larger populations will be will be more likely to intermarny either before or after the war (P1d) (see Supplementary Materials: Tables S1-S4). Finally there was some evidence for (Ple) such that that more educated individuals tended to marry resident Finns, although the pattern is slightly weaker for those married after the war. Before the war an uneducated Karelian has a 24\% (95\% HDI: 22\%-25\%) predicted probability of intermarriage which increases to 30\% for an educated Karelian (95\% HDI: 27\%-32\%). After the war an uneducated Karelian has a $61 \%$ (95\% HDI: 58\%-64\%) predicted probability of marying a resident Finn vs $68 \%$ (95\% HDI : $64 \%-72 \%)$ for an educated evacuee (see Figure 2a and Supplementary Material s: TableS1).

We found mixed support for the prediction (P2a) that evacuees who marry fellow Karelians will have more children. If they were married before the war they do have more children but this is not true for those who marry after the war. In particular, our model predicts that before the war an 'average' Karelian who marries another Karelian will have 0.23 more children -2.93 (95\% HDI: 2.83-3.01) children if they mary a fellow Karelian vs 2.70 (95\% HDI: $2.61-2.80$ ) children if they mary someone from westem Finland. After the war, however, the model predicts that marrying a fell ow evacuee results in 0.15 fewer children on average: 2.27 (95\% HDI : 2.14-2.33) children for Karelians who marry other Karelians vs 2.42 (95\% HDI: 2.32-2.50) for Kare ians who marny someone from the host popul ation (see Figure 4 and Supplementary materials: Table S2). There are al so differences between the mean age at marriage and age at first bi ith between evacuees who marry into the host population and those who mamy fellow Karelians. Before the war, both male and female evacuees who intermarry marry later and have their first child later than evacuees who marry other Karelians. The opposite pattern is seen for evacuees who marry after the war (see Table S8). Finally, cohort fertility estimates for non-Karelian Finns and Karelians bom between 1890 and 1940 suggest that non Karelian Finns have the same or slighty higher fertility rates as Karelians (see Supplementary material s: Table S9).

We al so found mixed support for the prediction (P2b) that evacuees who return to Karelia will have more offspring. An 'average' evacuee who marries before the war and returns is predicted to have 2.85 (95\% HDI: $2.76-2.94$ ) children if he or she retums and 2.85 (95\% HDI : 2.75-2.94) children if he or sheremains. For those who maried after the war, however, the model predicts that evacuees who return will have 0.20 more chil dren than those who remain - 2.35 (95\% HDI : 2.26-2.45) children for evacuees who retum vs 2.19 (95\% HDI : 2.10-2.27) for evacuees who remain (see Figure 2b, 4 and Supplementary materials Tables S1, S2 and S4). There was an interaction between intermarriage and retuming for evacuees who were married after the war, however. Evacuees who married after 1945 and returned to Karelia had higher reproductive outcomes if they married into the host population: 2.52 (95\% HDI : 2.41-2.61) for evacuees who married someone from western Finland vs. 2.27 (95\% 
HDI : 2.17-2.37) for evacuees who married fel low Karelians (Figure 4 bottom left panel). But this effect was even stronger for evacuees who remained in westem Finland throughout the war: 2.36 (95\% HDI : 2.29-2.44) for evacuees who married someone from western Finland vs. 2.02 (95\% HDI: 1.95-2.11) for evacuees who married fellow Karelians (Figure 4- bottom right panel).

Posterior distribution means and highest density intervals (HDI's) displaying the relative effect - the proportional change in an outcome induced by a single predictor - for models predicting 1) the probability of intermarriage and 2) reproductive outcomes for all predictors that do not overlap with zero are shown in Figures $2 \mathrm{a}$ and $2 \mathrm{~b}$ for all evacuees. For model results separated by those who were married before and after the war see Supplementary materials: Figures S1 and S2. For parameter estimates and 95\% HDI's for all predictors entered into all models see Supplementary materials: Tables S1-S4. Results of models run on the full sample of evacuees are shown in TableS1, results delimited by whether evacuees were married before or after the war are shown in Table S2, results of models separating evacuees into those who retumed to Karelia and those who remained in western Finland are shown in TableS3 and all combinations of these groups (i.e married before the war and returned, married before the war and remai ned, married after the war and returned and married after the war and remai ned) are shown in TableS4.

Summary statistics and frequencies are shown in Supplementary Materials: Description of Data and Tables S5-S9. Variables that were not entered into the model s are discussed in Supplementary Material s: Variables Dropped from Models. Themean age of the individuals we used in our models was 31 years old when the war began (for evacuee age distribution see Supplementary Materials: Figure S5).

The results of our analysis point to the importance of considering tradeoffs between the social and reproductive benefits generated by maintaining within group bonds and social networks and the economic benefits that may be gained through integration and what are likely to be weaker bridging social ties. Understanding the conditions that facilitate the integration of displaced populations into host societies has received considerable attention and much of this research has focused on attempting to explain the causes of conflict between immigrant and host communities while expl oring policies that are expected to build social capital. A fundamental concem of this effort, however, is the need to understand the costs and benefits of bonding and bridging social networks. Our analysis indicates that bonding social networks enhance reproductive outcomes and that bridging social networks offer opportunities to improve social and economic outcomes.

Overall, these results suggest that integration involves a trade-off between reproduction and status. For all evacuees, remaining in western Finland; getting an education, working in technical professions, offices, and non-agricultural occupations; and hypergamy (i.e marrying someone from a higher social class) all predict an increased probability of marrying someone from western Finland. However, many of these same factors that predict social integration al so predict lower reproductive outcomes (see Supplementary Materials: Table S1) and these tradeoffs change in important ways both in the pre and post-war environments (Table S2) and between evacuees who return to Karelia and evacuees who remain in western Finland (Table S3). Younger evacuees, for example, are more likely to marry into the host population after the war ends while evacuees who return to Karelia are less likely to intermarry both before and after the war. Although education is positively associated with the probability of marnying someone from westem Finland before the war, it does not predict marrying into the host population after the war (TableS2). Perhaps this is because education, which is often seen to produce stronger bridging ties between individual ${ }^{44}$, plays a more important role in integration when families and extended families are geographically separated which was probably more often the case prior to the war. Intermarriage, meanwhile, is positively associated with hypergamy for evacuees who marry both before and after the war (Figure 2a and 3, Table S2) whereas returning to Karelia negatively predicts the probability of intermarriage for all evacuees. Regardless of when they were married, evacuees who remain in westem Finland are not only more likely to marry people from western Finland, they are more likely to marry up when they do. Although this is hardly surprising for evacuees who marry before the war (eg. they havea Karelian spouse and are likely to have stronger ties to Karelia), it is interesting that unmarried individuals who remain in western Finl and throughout the war are more likely to marry someone from a higher social class if they marny into the host population. This suggests that there may be a dual benefit associated with more rapid assimilation (i.e remai ning and intermarnying) after the war. It is important to note, however, that socioeconomic status is not the only thing being traded in marriage markets and that preferences for marying within one's own group and class often differs between social classes and occupations. A study from 1990's Sweden, for example, showed that age was the best predictor of intermarniages between native born Swedes and immigrants ${ }^{45}$ and both lower classes and non-farmers were shown to be the most likely to marry outside of their own socio-economic class in modern day Finland ${ }^{46}$. Amongst the Karelian evacuees, however, the positive association between hypergamy and intermarriage seems to be primarily driven by Karelian men marrying higher status women from the host population. Although before the war both sexes are equal ly likely to intermary, after 1945, men are more likely to do so. Together these findings suggest that the peculiar conditions of the mating market after the war may play an important role whereby femal e biased post-war sex ratios (e.g. due to excess male mortality during the war) drive mate choice such that men are now better able to choose who they marry than women.

Karelians who marry western Finns beforethewar have fewer children than those who marry other Karelians while evacuees 
who marry western Finns after the war have more children, particularly if they remained in westem Finland throughout the war (see Figure 2a and 4). To make sense of this result it is useful to consider the differences between the pre war and post-war environments. Before the war, Karelians were the majority ethnic group living in Karelia. Therefore, if you married a non Kare ian before the war, you and your non-Kare ian spouse, are likely to be both geographically and culturally separated from many of the tight ingroup social networks (eg. family members and friends) that build bonding social capital. After 1945, however, Karelians are a minority group living in a new place in western Finland. In this situation having a non-Karelian spouse may not be as detrimental to the maintenance of tight within group social networks. In fact having a spouse from western Finland may actual ly be a benefit as you are able to form tight social bonds with individuals and family members who are now your neighbors. The higher fertility outcomes among evacuees who remaining in western Finl and throughout the war further supports this interpretation and suggests that when the Karelians who remain al so end up mamying into the host population, they may be better able to develop new social connections. This indicates that rapid assimilation (i.e. remaining and intermarying) by a minority group when they are young enough (Pla) may help to mitigate the reproductive ded ines more generally associated with integration. Therefore, al though these results fit within the framework of a growing body of research showing that intergroup marriages can reduce fertility, ${ }^{29}$ the pre and post-war fertility differences for Karelians who intermarry suggest that these outcomes al so depend on the degree of geographic and cultural assimilation of the migrant population. On the other hand, evacuees who mary resident Finns after the war al so marry earlier and have their first child at a younger age than evacuees who marry other Karelians, opposite to the pattern we see before the war (Supplementary materials: Table S8). This suggests that it may simply be harder to find a Karelian spouse after the war when Karelians are now in the minority. It shoul d be noted that, al though these data include individual s who did not report having any children, they are representative of a demographical ly unstable population and do not include individuals who were never married. Therefore we must be careful not to infer evolutionary fitness from these results. It should al so be noted, however, that these discordant reproductive outcomes are unlikely to be driven by differences in fertility rates between Karelians and western Finns because data over this period suggest that non-Karelian Finns have the same or slightly higher fertility rates as Karelians (Table S9).

We found no evidence to support All port's ${ }^{13}$ contact hypothesis that larger, more diverse communities which encourage more frequent interactions between different groups of people will promote integration. None of the models showed any relationship between the population of one's birthplace and either the probability of intermarrying or reproductive outcomes. However, it is important to recognize that these data may not offer the best test of the contact hypothesis. There are many reasons that migrants may decide to intermamy and remain in the host community (e.g. empl oyment, social services, where you were placed and what you left behind) that are unrel ated to the tolerance and openness of the host population. In addition, the dramatic decline in class differences following the war, the government intervention and the high post war intermarriage rate (75\%) offers some limited support for All port's contention that a precondition of successful integration is equal status between groups. Nevertheless, the population of the towns in which Karelians were bom does not seem to impact on the probability of intermarriage or reproduction.

The conditions that impact the reproduction and integration of the Karelian evacuees can be understood within the framework of evolutionary theory. The ecol ogical constraints placed on refugees, including war and an evacuation can have predictable effects on their behavior, such as who they marry, whether or not they return to their place of birth given the opportunity, and when they start reproducing, all of which can affect social capital. Human groups are organized around marriage, kinship and reciprocity ${ }^{47}$ and there is good evidence for parochial al truism - the tendency to direct al truism preferential ly towards one's own group and eschew interactions with outsiders ${ }^{28}$. If natural selection has favored this type of tribalism (i.e preferential interactions with ingroup members and hostility towards outgroups) then humans may be predisposed towards sanctioning individuals who develop bridging social ties and attempt to integrate. An anal ysis of the reproductive consequences of marriages in a tribal society in the Amazon showing that parents and brothers have higher lifetime reproductive success when their respective chi ldren and sisters marry more cl osely related individuals supports thi i interpretation ${ }^{47}$. Therefore, the increased fertility associated with marrying within one's own cultural group and returming to Karelia in the population studied here can be viewed as the result of adaptations favoring parochialism and bonding social networks ${ }^{28}$. At the same time bridging social networks and community integration have been cited as two of the most important factors predicting intergenerational upward social mobility in the United States ${ }^{48}$ and a study of economic outcomes from the Karelian evacuation showed that the incomes of mal e evacuees increased compared to Finni sh men who were not di splaced ${ }^{49}$. Parochialism may therefore have social and economic costs which may include missed opportunities to marry into a higher social class. Nevertheless, some groups may be able to successfully gain the economic benefits of integration without experiencing the costs of reduced fertility and it is interesting to note that in our study farmers who owned larger pl ots of land were both more likely to intermamy and had higher fertility after the war. Overall, however, in an increasingly global economy the benefits of bonding social capital including increased security, solidarity, within group trust and mutual aid may be offset by restricted freedom of movement, reduced economic opportunities and less integration.

Our results indicate that many of the same variables affect reproduction and integration oppositely. Intermarriage rates 
between the migrant and host populations are a commonly used metric to assess social integration ${ }^{50}$ and intermarriage is commonly viewed by immigrants as the final step in the process of integration ${ }^{51}$. Therefore, intermarriage provides strong but indi rect evidence that boundaries between groups have weakened and that migrants who intermamy are being exposed to natives by living in the same neighborhoods, attending the same schools and sharing the same socioeconomic status ${ }^{52}$. Another commonly used marker of social integration, however, is the length of time spent in the host community ${ }^{52}$ while returning to one's natal community is frequently used to assess bonding social capital. Although the ability to return home shortly after a forced migration is rarely avai lable for refugees from war, this opportunity is common for refugees from natural di sasters. An anal ysis of evacuees from hurricane Katrina in the United States, for example, found that tighter social networks amongst the Vietnamese resulted in them returning at much higher rates than A frican A mericans ${ }^{53}$. Other studies have suggested that this was al so the case for the Katrina diaspora more generally and that the size of social networks amongst family and friends predicted the probability of individuals returning to New Orleans ${ }^{54}$. However, even when refugees have the opportunity to return home, not all of them do and they are rarely displaced a second time, so the Karelian evacuees all ow us to compare the life outcomes of individuals all living in the same place at the same time.

Although we are using intermarriage and the probability of reverse-migration to measure an individual's level of social integration, these variables are likely to be both a cause and an effect of integration and neither variable is exogenous to the model. In other words, individual s who have more bridging social connections are more likely to intermarny and remai $n$ in the host society while those with more bonding social connections are more likely to marry within their own group and return to their natal communities which only serves to further strengthen their respective bridging and bonding social networks ${ }^{24}$. It is al so important to note that, al though we have used intermarriage as a proxy to measure integration and used the social class (i.e. occupation) of one's spouse to measure economic and social success, any broader interpretation of these results depends in large part on how these key concepts are defined. The evacuations from Karelia were part of the largest mass exodus in history during World War II in which an estimated 60 million people were forcibly di splaced ${ }^{55}$. Our anal yses suggest that many of these evacuees faced a tradeoff between the economic benefits of integration and fertility benefits associated with maintaining strong ties within the Karelian di aspora. These findings are of general interest across academic discipl ines and have significant implications for public policy. Europe is currently facing the largest influx of refugees since World War II and the European Union has identified a list of basic principles to hel p immigrants integrate including finding empl oyment and trying to increase the frequency of interactions between immigrants and natives ${ }^{56}$. In Germany, fewer than $15 \%$ of first time asylum applicants had gone to University and reports suggest that less educated immigrants struggl e disproportionatel $y^{57}$. Overall, however, our results indicate that evacuees who intermarny and remain in the host society gain socioeconomic benefits but suffer reduced fertility which suggests that integration invol ves trade-offs between within group 'bonding' social networks and between group 'bridging' networks.

\section{Methods}

All methods and statistical analyses were pre registered on November 30, 2017 which was prior to our accessing these data. The predictor variables, outcome variables, model selection criteria and proposed analyses outlined bel ow are nearly identical to those identified in the Open Science Framework pre-registration ${ }^{58}$. All discrepancies and their rational e are identified in Supplementary Materials: Pre registration. All R code used to select and transform the data, run the models and construct the figures can be found on this Github repository: ht $t$ ps: / / gi t hub. cond r ober t I ynch66/ NHB_ns_revi si ons or in the 'Supplementary software' section.

Data

Structured interviews of Karelian evacuees were published in a four volume set called 'Siirtokarjalai sten tie' 59 . The project was part of an effort to record the lives of the Karelian migrants. Over 300 individuals were trained to conduct these interviews which took place between 1968 and 1970 and an effort was made to locate all people who were evacuated from Karelia during the war. Each entry in the publ ished books lists the name, sex, date of birth, birthplace, occupation, year of marriage, reproductive records (name, sex, and date of birth of all children), membership in various organizations and the years and names of all places where they have lived from birth until the time they were interviewed. If they were married, the name, date of birth, birthplace and occupation of their spouse are al so listed. These books were scanned and software was developed (Kaira Core and Natural Language Processing (NLP) software designed for use with the Finnish language) to digitize and extract the records (see Loehr et al $^{60}$ for a detail ed description of data extraction methods and the MiKARELIA database). We extracted their name, sex, year of birth, occupation, spouse, spouse's occupation, the names of all places they had lived and the years they moved, their year of marriage and their number of children. Overall there are data on approximately 250,000 individuals, including children and spouses. Here we focus on a subset $(N=26,757)$ of individuals who were were born in Karelia, lived in Karelia immediately prior to the Soviet invasion in 1939, were between 14 and 70 years old when the first evacuation occurred (so that they were sexual ly mature when the war began) and for whom we had complete data regarding their sex, year of birth, birthplace, occupation, education, number of children, movements, wedding year, spouse's occupation and spouse's birthplace. 
The most limiting factor was wedding year which was missing for $51 \%$ of the sample. No statistical methods were used to pre-determine sample sizes but our sample sizes are comparable to those used by Kul ${ }^{29}$ and larger than those reported in other previous publications ${ }^{49}$ (see Supplementary Information: Missing Data and Selection Bias).

Outcome variables 1 ) a dummy variable measuring whether an individual intermarried was created to measure social integration and 2) number of offspring produced before the evacuees were interviewed in 1970 was used to measure lifetime reproductive success.

Predictor variables in all models were sex (1=male), age (in years), logged population of birthplace, hypergamy categorical ordinal rankings for individuals who married someone of lower (-1), same (0) or higher social class (1), dummy variables for the following 7 occupations: technical professionals, office workers, business, agricultural, transportation, factory workers and the service industry, a dummy variable indicating whether or not a particular occupation required an education ( $1=y e s$ ), a dummy variable indicating whether or not they were married after 1945 ( $1=y e s$ ) and a dummy variable indicating whether or not they returned to Karelia during the war ( $1=y e s$ ). Place of birth was entered as a random effect into all models. For all models predicting reproductive outcomes, intermarriage (married a Karelian or married a resident Finn) was added as a covariate. Populations of towns located in Finland were obtained from the 1950 census Statistics Finland which lists the number of individuals who were bom in each location in Finl and at the time they were censused in $1950^{61}$ — the closest census to the Soviet invasion - and the populations of Karelian towns were obtained by conducting searches for the old town names, most of which have their own Wikipedia page, and entering the population estimate for the town immediately prior to the Soviet invasion. Social class, which was used to determine hypergamy, was organized into 7 ordered groups as defined by Waris for 1940 Finland ${ }^{62}$. There were 1,580 di stinct occupations listed and they were organized into seven categories as defined by the 1950 Finnish census (For details regarding the coding of both social class and occupation (see Supplementary Material s: Social status and occupations). We al so flagged individuals if either they or their spouse were members of a Karelian society call led 'Karjalaseura' which was founded in 1940 as a way to connect with other evacuees and aims to promote and preserve Karelian culture.

Data normalization The populations of birthplaces were natural log transformed and scal ed to val ues between 0 and 1 with higher val ues representing larger popul ations. Age was cal ibrated from birth year to reflect an evacuees age in years at the time of the evacuation.

Statistical Analysis We used Bayesian inferencefor all statistical anal yses. In aBayesian framework, each model conditions data on prior probability distributions and uses Monte-Carlo sampling methods to generate posterior distributions for the parameters. The priors are the initial probabilities for each possi ble val ue of each parameter. This type of analysis allows us to compare posterior distributions across occupational categories, sexes, age groups, marriage types and migration profiles without relying on specific post-hoc tests ${ }^{63}$ and obviates the need to adjust for multiple comparisons ${ }^{64}$. We are al so better able to visualize and interpret differences between parameter estimates relative to a specific value by reporting and displaying the entire posterior distribution for each predictor and showing the highest density intervals (HDI) which reveal the most credible val ues for each parameter estimate. Here we assume that 95\% highest density intervals which do not include zero are evidence that the parameter value is credibly different from the baseline.

To anal yze which factors predict the probability of an evacuee intermarnying and which predict reproductive outcomes we ran models on the full sample of evacuees for which we had complete data (see above) $(\mathrm{N}=26,757)$ and included interactions between sex and age and both returned to Karelia and married after 1945. We al so entered an interaction between married after the war and hypergamy for the intermarriage model only. For the reproductive outcomes models we al so incl uded additional interactions between intermarriage and sex, hypergamy, married after the war and returned to Karelia (see Supplementary Materials: Model Selection and Interactions and Table S10). These interactions were included because we were primarily interested in anal yzing differences between evacuees who returned to Karelia and those who did not while al so understanding that the environment and mating market was very different before the war when Karelians were all living together and after the war when they were all living in their host cities or towns (see pre registration: https://osf.io/dvkfz/). Because there were many significant interactions between the two key dummy variabl es 'married after 1945' and 'returned to Karelia' (see TableS1 and Figures $2 \mathrm{a}$ and $2 \mathrm{~b}$ ) and because these variables were central to our hypotheses and all of our models, we further subdivided the data into the following groups - evacuees who married before the war ended in 1945, evacuees who married after the war ended (Figure, evacuees who returned to Karelia during the war and evacuees who remained in westem Finl and throughout the war - and ran models on all combinations of these groupings (seetables S1-S4 and Figures S1-S2). For more detail s on model validity, posterior predictive checks and detai led model specifications seeSupplementary materials: Model validity, effects and specifications.

Factors affecting the probability of intermarriage

A Bayesian General ized Linear Mixed Effects Model (GLMM) Logistic Regression was designed to assess which factors predict the probability of intermarriage (i.e marrying someone from western Finland) (Supplementary materials: FigureS1 and TableS1 - top pane). These data were subdivided between evacuees who married before and after the war (Figures 2a and 
3 and Supplementary materials: Table S2) to test the foll lowing predictions about how these factors differential ly affect who evacuees marry before the war when they are living in Karelia and who they marry after the war after ends when they are living in western Finland: Both before and after the war (Pla) younger evacuees, (P1b) evacuees who returned to Karelia during the war, (P1d) evacuees who were bom in places with larger popul ations and (Ple) more educated evacuees will be more likely to intermarny and after the war (P1c) evacuees who marny into the host population will be more likely to marry someone someone froma higher social class.

Factors affecting reproductive outcomes

A Bayesian General ized Linear Mixed Effects Model (GLMM) Poisson Regression was designed to assess reproductive outcomes and to test the following predictions: (P2a) evacuees who marny other Karelians and (P2b) evacuees who return to Karelia between 1941 and 1944 will have more children across all birth cohorts, occupations, sexes and social classes (Supplementary materials: Figure S2 and Table S1- bottom pane). Although these predictions were made for evacuees regardless of when they were married, we al so subdivided the data into evacuees who married before the war and those who married after the war to determine if these differences are impacted by the significant differences betwen pre and post-war environments (Figures $2 \mathrm{~b}$ and 4 and Supplementary material s: Table S2). Because some weight was assigned to two different models used to predict reproductive outcomes (see Supplementary materials: Model Selection and I nteractions, and Table S10), all predictions in the results section and predictions used to construct figure 4 use the 'ensemble' function in the 'rethinking' package in $\mathrm{R}$ to weigh predictions by their respective model weights.

\section{References}

1. Greenwood, P. J. Mating systems, phi lopatry and dispersal in birds and mammal s. Anim Behav. 28, 1140-1162 (1980).

2. Stephen Dobson, F. Competition for mates and predominant juvenile male dispersal in mammals. Anim Behav. 30, 1183-1192 (1982).

3. Emlen, S. T. The evolution of helping. i. an ecological constraints model. The Am Nat. 119, 29-39 (1982).

4. West, S. A. et al. Cooperation and the scal e of competition in humans. Curr. Biol. 16, 1103-1106 (2006).

5. Ortega, F. \& Peri, G. The causes and effects of international migrations: Evidence from OECD countries 1980-2005 (2009).

6. Glazer, N. \& Moynihan, D. P. Beyond the Melting Pot: The Negroes, Puerto Ricans, J ews, Italians and Irish of New York City. (1963).

7. Hamilton, W. D. The genetical evolution of social behaviour. I. J. Theor. Biol. 7, 1-16 (1964).

8. Trivers, R. L. The evolution of reciprocal al truism Q. Rev. Biol. 46, 35-57 (1971).

9. Greenwald, B. C. \& Stiglitz, J. E. Externalities in economies with imperfect information and incompletemarkets. Q. J . Econ. 101, 229 (1986).

10. Lawrence, P. R. \& Lorsch, J. W. Differentiation and integration in complex organizations. Adm Sci. Q. 12, 1-47 (1967).

11. Putnam, R. D., Leonardi, R. \& Nanetti, R. Y. Making Democracy Work: Civic Traditions in Modern Italy (Princeton University Press, 1994).

12. Putnam, R. Bowling al one: The collapse and revival of American community (Simon and Schuster, New York, 2000).

13. Allport, G. W. The nature of prejudice (Addison, Wesley;, New York, 1954).

14. Pettigrew, T. F. \& Tropp, L. R. A meta-analytic test of intergroup contact theory. J. Pers. Soc. Psychol. 90, 751-783 (2006).

15. Olson, M. Logic of CollectiveAction: Public Goods and the Theory of Groups (Harvard economic studies. v. 124) (Harvard University Press, 1965).

16. Alesina, A. \& La Ferrara, E. Participation in heterogeneous communities. Q. J. Econ. 115, 847-904 (2000).

17. Friedberg, R. M. You can't take it with you? immigrant assimilation and the portability of human capital. J. Labor Econ. 18, 221-251 (2000).

18. Horvat, E. M., Weininger, E. B. \& Lareau, A. From social ties to social capital: Class differences in therelations between schools and parent networks. Am Educ. Res. J. 40, 319-351 (2003).

19. Borjas, G. J. Assimilation, changes in cohort qual ity, and the eamings of immigrants. J. Labor Econ. 3, $463-489$ (1985).

20. Quillian, L. Prejudice as a response to perceived group threat: Population composition and Anti-Immigrant and racial prejudice in europe. Am Sociol. Rev. 60, 586-611 (1995). 
21. Fennelly, K. \& Federico, C. Rural residence as a determinant of attitudes toward US immigration policy. Int. Migr. 46, 151-190 (2008).

22. Marsden, P. V. Core discussion networks of americans. Am Sociol. Rev. 52, 122-131 (1987).

23. Bott, E. \& Spillius, E. B. Family and social network: Roles, norms and external relationships in ordinary urban families (Routledge, 2014).

24. Bevelander, P. \& Irastorza, N. Economic integration of intermarried labour migrants, refugees and family migrants to sweden: Premiumor selection? (2014).

25. Boustan, L. P., Fishback, P. V. \& Kantor, S. The effect of internal migration on local labor markets: American cities during the great depression. J. Labor Econ. 28, 719-746 (2010).

26. Wilson, S., Bassiou, E., Denli, A., Dolan, L. C. \& Watson, M. Traveling groups stick together: How collective directional movement influences social cohesion. Evol. Psychol. 16, 1474704918792134 (2018).

27. Silk, J. B., Alberts, S. C. \& Altmann, J. Social bonds of femal e baboons enhance infant survival. Science 302, 1231-1234 (2003).

28. Choi, J.-K. \& Bowles, S. The coevolution of parochial altruismand war. Science 318, 636-640 (2007).

29. Kulu, H. et al. Fertility by birth order among the descendants of immigrants in sel ected european countries. Popul. Dev. Rev. 43, 31-60 (2017).

30. Pailhé, A. The convergence of second-generation immigrants' fertility patterns in france: The role of sociocultural distance between parents' and host country. Demogr. Res. (2017).

31. Jejeebhoy, S. J. Women's education, autonomy, and reproductive behaviour: Experience from developing countries. OUP Catalogue (1995).

32. Coleman, D. A. Trends in fertility and intermarriage among immigrant populations in western europe as measures of integration. J . biosocial science 26, 107-136 (1994).

33. Goldscheider, C. \& Uhlenberg, P. R. Minority group status and fertility. AJ S 74, 361-372 (1969).

34. Hacker, J. D. \& Roberts, E. The impact of kin availability, parental religiosity, and nativity on fertility differentials in the late 19th-century united states. Demogr. Res. (2017).

35. Sosis, R. Why aren't weall hutterites? Hum Nat (2003).

36. Wiley, N. F. The ethnic mobility trap and stratification theory. Soc. Probl. 15, 147-159 (1967).

37. Wilensky, H. L. \& Edwards, H. The skidder: Ideological adjustments of downward mobile workers. Am Sociol. Rev. 24, 215-231 (1959).

38. Kramer, K. L. Cooperative breeding and its significance to the demographic success of humans. Annu. Rev. Anthropol. 39, 417-436 (2010).

39. Sear, R. \& Coall, D. How much does family matter? cooperative breeding and the demographic transition. Popul. development review 37, 81-112 (2011).

40. Portes, A. \& Sensenbrenner, J. Embeddedness and immigration: Notes on the social determinants of economic action. Am J. Sociol. 98, 1320-1350 (1993).

41. Lavery, J. E. The history of Finland (Greenwood Publishing Group, 2006).

42. Haapala, P. \& Toivo, R. M. Suomen historian kartasto (Karttakeskus, 2007).

43. Syrjänen, K., Honkola, T., Lehtinen, J., Leino, A. \& Vesakoski, O. Applying population genetic approaches within languages: Finnish dial ects as linguistic populations. Lang. Dyn. Chang. 6, 235-283 (2016).

44. Granovetter, M. Thestrength of weak ties: A network theory revisited. Sociol. theory 201-233 (1983).

45. Elwert, A. et al. Opposites attract-evidence of status exchange in ethnic intermarriages in sweden. Lund Pap. Econ. Hist. Popul. Econ. 147 (2016).

46. Mäenpää, E. Homogamy in educational level and parental social class in finland: A log-linear analysis. Eur. Sociol. Rev. 31, 253-267 (2014).

47. Chagnon, N. A., Lynch, R. F., Shenk, M. K., Hames, R. \& Flinn, M. V. Cross-cousin marriage among the yanomamö shows evidence of parent-offspring conflict and mate competition between brothers. Proc. Natl. Acad. Sci. U. S. A. 114, E2590-E2607 (2017). 
48. Chetty, R., Hendren, N., Kline, P. \& Saez, E. Where is the land of opportunity? The geography of intergenerational mobility in the United States. Q. J. Econ. 129, 1553-1623 (2014).

49. Sarvimäki, M., Uusitalo, R. \& Jantti, M. Long-term effects of forced migration. (2009).

50. Pagnini, D. L. \& Morgan, S. P. Intermarriage and social distance among U.S. immigrants at the turn of the century. Am J . Sociol. 96, 405-432 (1990).

51. Qian, Z. \& Lichter, D. T. Social boundaries and marital assimilation: Interpreting trends in racial and ethnic intermarriage. Am Sociol. Rev. 72, 68-94 (2007).

52. Lichter, D. T., Qian, Z. \& Tumin, D. Whom do immigrants mary? emerging patterns of intermarriage and integration in the united states. Ann. Am Acad. Pol. Soc. Sci. 662, 57-78 (2015).

53. Li, W., Airriess, C. A., Chen, A. C.-C., Leong, K. J. \& Keith, V. Katrina and migration: Evacuation and retum by African Americans and Vietnamese Americans in an eastern New Orleans suburb. Prof. Geogr. 62, 103-118 (2010).

54. McCarthy, K. F., Peterson, D. J., Sastry, N. \& Pollard, M. The repopulation of New Orleans after Hurricane Katrina (Rand Corporation, 2006).

55. Shephard, B. The long road home: the aftermath of the second world war. (2010).

56. $\mathrm{Cec}, \mathrm{A}$. Common Agenda for Integration-Framework for the Integration of Third-Country Nationals in the European Union". Commun. fromComm to Counc. Eur. Parliam Eur. Econ. Soc. Comm Comm Reg. COM 389.

57. Economist, T. How germany is integrating its refugees. https://www.economist.com/news/europe/ 21728992-it-seems-be managing-how-germany-integrating-its-refugees (2017). Accessed: 2018-2-4.

58. Lynch, R., Lynch, E., Loehr, J., Pettay, J \& L Lummaa, V. How social class and occupations predict migration patterns and assimilation of forced migrants in wartime finland. (2017).

59. Anonymous. Siirtokarjalaisten tie (Nyky-Karjala, Turku, Finland, 1970).

60. Loehr, J., Lynch, R., Mappes, J., Sal mi, T., Pettay, J. and Lummaa, V. Newly digitized MiKARELIA database reveals the journeys of second world war forced migrants from finni sh karelia. Finn. Yearb. population Res. (2017).

61. Hytönen, T. Sodaniälkeisen asutustoiminnan vai kutus suomen väestökehitykseen (2007).

62. Waris, H., Jyrkilä, V., Raitasuo, K. \& Siipi, J. Siirtoväen sopeutuminen. Tutkimus Suomen karjalaisen siirtoväen sosiaal isesta sopeutumisesta. Helsinki: Otava (1952).

63. McEl reath, R. Statistical rethinking. texts in statistical science (2015).

64. Gelman, A., Hill, J . \& Yajima, M. Why we (usually) don't haveto worry about multiplecomparisons. J. Res. Educ. Eff. 5, 189-211 (2012).

\section{DATA AVAILABILTY}

The data that was used to generate these results and that supports the findings of this study are available on Github: https://github.com/robertlynch66/Migrations-revisions-NHB

\section{CODE AVAILABILTTY}

The code used to produce these models, generate all results and produce all of the figures and tables in this manuscript and the supplementary information is avai lable on Github; https://github.com/robertlynch66/Migrations-revisions-NHB and is also included in 'Supplementary Software'.

\section{ACKNOWLEDGEMENTS}

This research was supported by the Kone foundation. The funders had no role in study design, data collection and analysis, decision to publ ish or preparation of the manuscript. We would al so like to thank J enni Pettay for hel p for hel ping to translate much of the source data from Finni sh to Engl ish and J uuso Kal lioniemi and Tuomas Sal mi for hel ping to extract the data from the original texts.

\section{COMPETING INTERESTS}

The authors declare no competing interests. 


\section{AUTHOR CONTRIBUTIONS}

R.L. wrote the first draft of the manuscript, conducted the statistical analysis and made the figures and tables. K.P and K.M. hel ped design the statistical models. J.L. and V.L. planned the study and oversaw data collection. All authors hel ped to write and edit the manuscript.

\section{FIGURES}

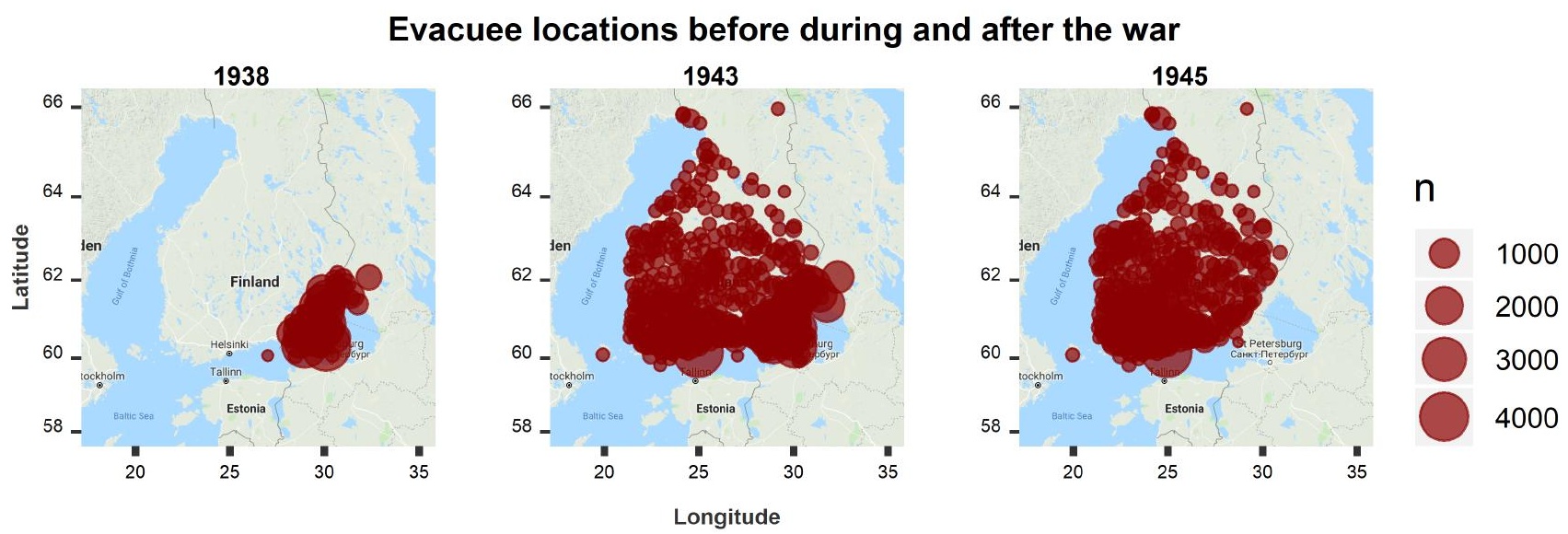

Figure 1a-c: Evacuee locations before (1938) during (1943) and after the war (1945). The Karelian region, located in southeasterm Finland, was ceded to the Soviet Union twice during the war. The first evacuation took place 1939-40, followed by a resettling of Karelia starting in 1941 and a second evacuation occurring in 1944. For an animation of Karelian moves over time please

seeht t ps: / / www. hel si nki . fi / en/ pr oj ect s/ / ear ni ng- f rom our - past / dat a\#sect i on- 60700). 

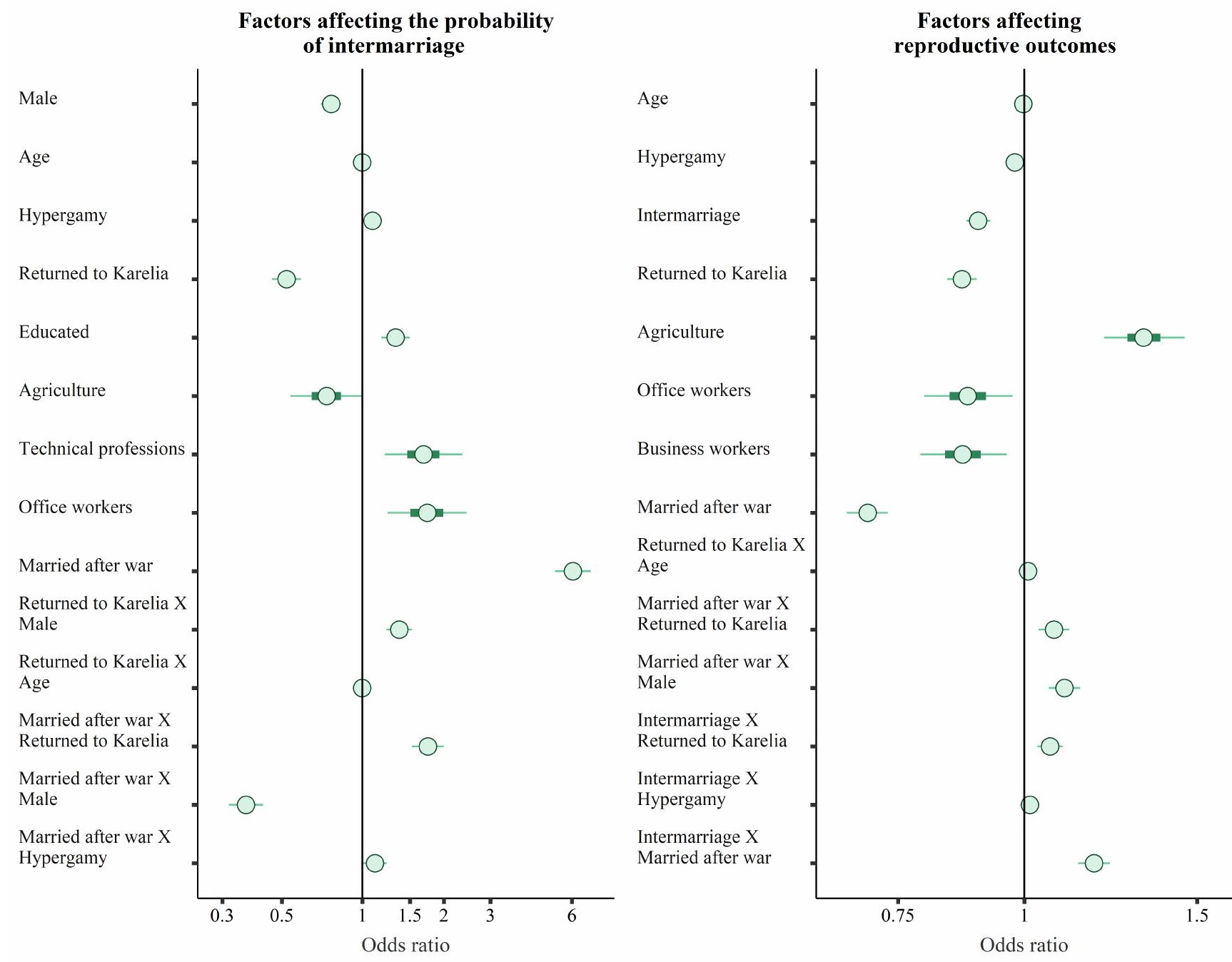

Figures 2a-2b: Posterior distribution credibility intervals for factors affecting the probability of intermarriage (left panel) and number of children (right panel) for all evacuees (mean value- open circle, 50\% HDI - thick line, thin line 95\% HDI). Distributions display the proportional change in the outcome (i.e. relative effect) induced by each predictor. Only fixed effects and interactions with 95\% HDI 's that do not overlap with 0 are shown (see Supplementary Table S1 for mean estimates and 95\% HDI's for all parameters entered into the mode; Supplementary Table S5 for mean differences in the number of children of evacuees contingent upon both who they married (i.e. resident Finn or Karelian) and Supplementary Table S7 for percentages and sample sizes of social status differences between spouses who married resident Finns and those who married fellow Karelians both before and after the war. 
MARRIED BEFORE THE WAR

Returned to Karelia

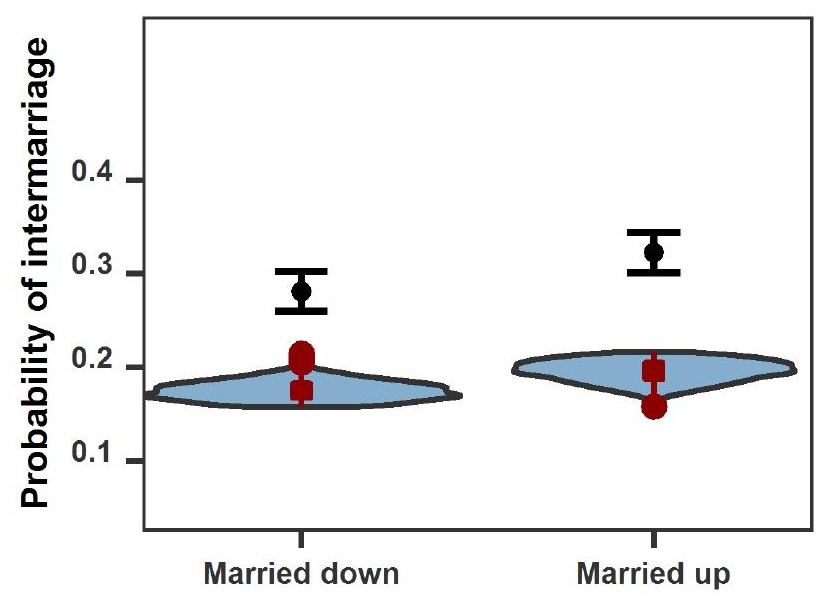

Social class of spouse
Remained in western Finland

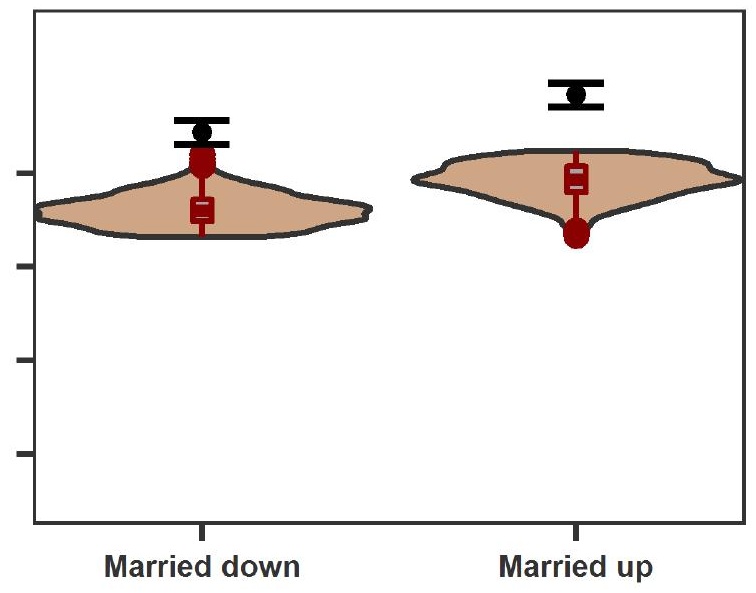

Social class of spouse

MARRIED AFTER THE WAR

Returned to Karelia

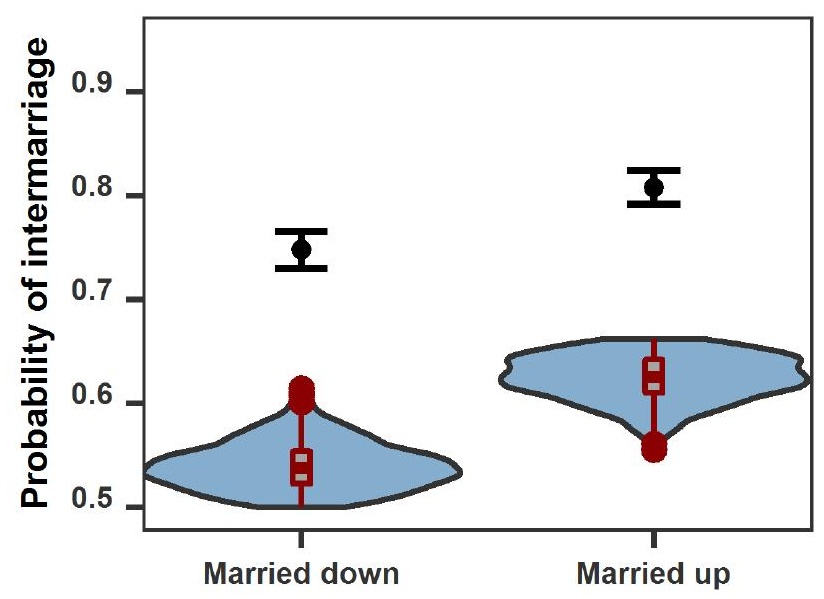

Social class of spouse
Remained in western Finland

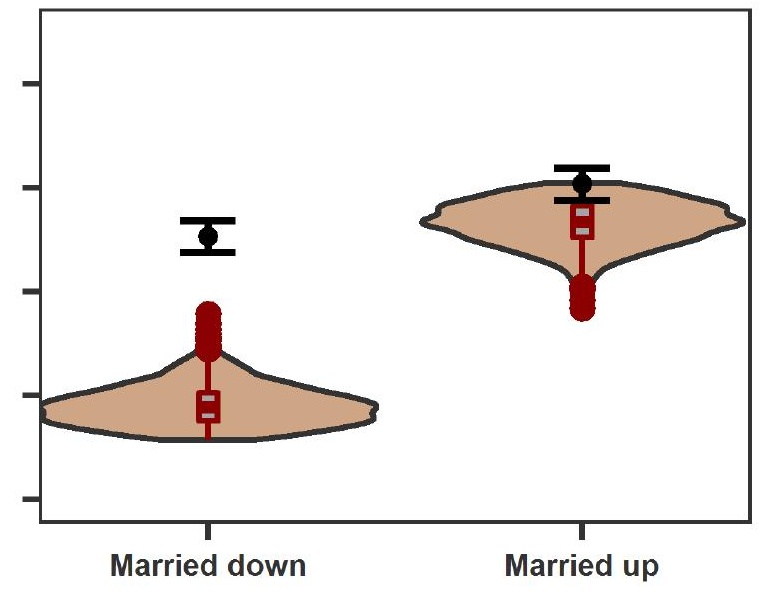

Social class of spouse

Figure 3: Intermarriage is positively associated with marying up both before and after the war. Posterior distribution predictions are generated from the full model shown in the top panel of Table S1 ( $N=26,757)$. Before the war (top panels) Karelians who intermarry are both more likely to marry up ( $X$ axis - right side higher than left; see al so Table S2 top pane: Hypergamy, mean $0.10,95 \% \mathrm{Cl} 0.06$ to 0.16 ) and more likely to remain in western Finland during the war (brown higher than blue; see al so Table S2 top panel: Retumed to Karelia, mean $0.57,95 \% \mathrm{Cl}-0.71$ to -0.45 ). After the war (bottom panels) the same pattern is evident. Evacuees who intermarny are al so more likely to marry up ( $X$ axis - married up higher than married down; see also Table S2 third panel: Hypergamy, mean $0.09,95 \% \mathrm{Cl} 0.00$ to 0.17 ) and this is particularly true for those who remained in western Finland during the war (Married up category on lower right panel (brown) is higher than married up posterior (blue) on lower left pane; see al so TableS2 third panel: Returned to Karelia, mean $0.20,95 \% \mathrm{Cl}-0.04$ to 0.44 ) ). In other words, both before and after the war the probability of marying down is higher for evacuees who married fellow Karelians and for evacuees who retumed to Karelia whi le the probabi lity of marrying up is higher for individuals who remain in western Finland throughout the war and married a western Finn (see Supplementary Materials Table S1 and S2 for full models and Tables S5 and S7 for observed data sample sizes and percentages). Model predictions (posterior distributions) are less pronounced than differences are in the raw data (error bars) before and after the war because the posterior predictions account for all of the additional variables and interactions entered into the model. The posterior distribution plots (filled in) include the model predicted 95\% highest density intervals with the lower and upper hinges of the box plots correspondi ig/it5 the first and thi rd quartiles. Error bars with points are the observed value means and standard errors. 

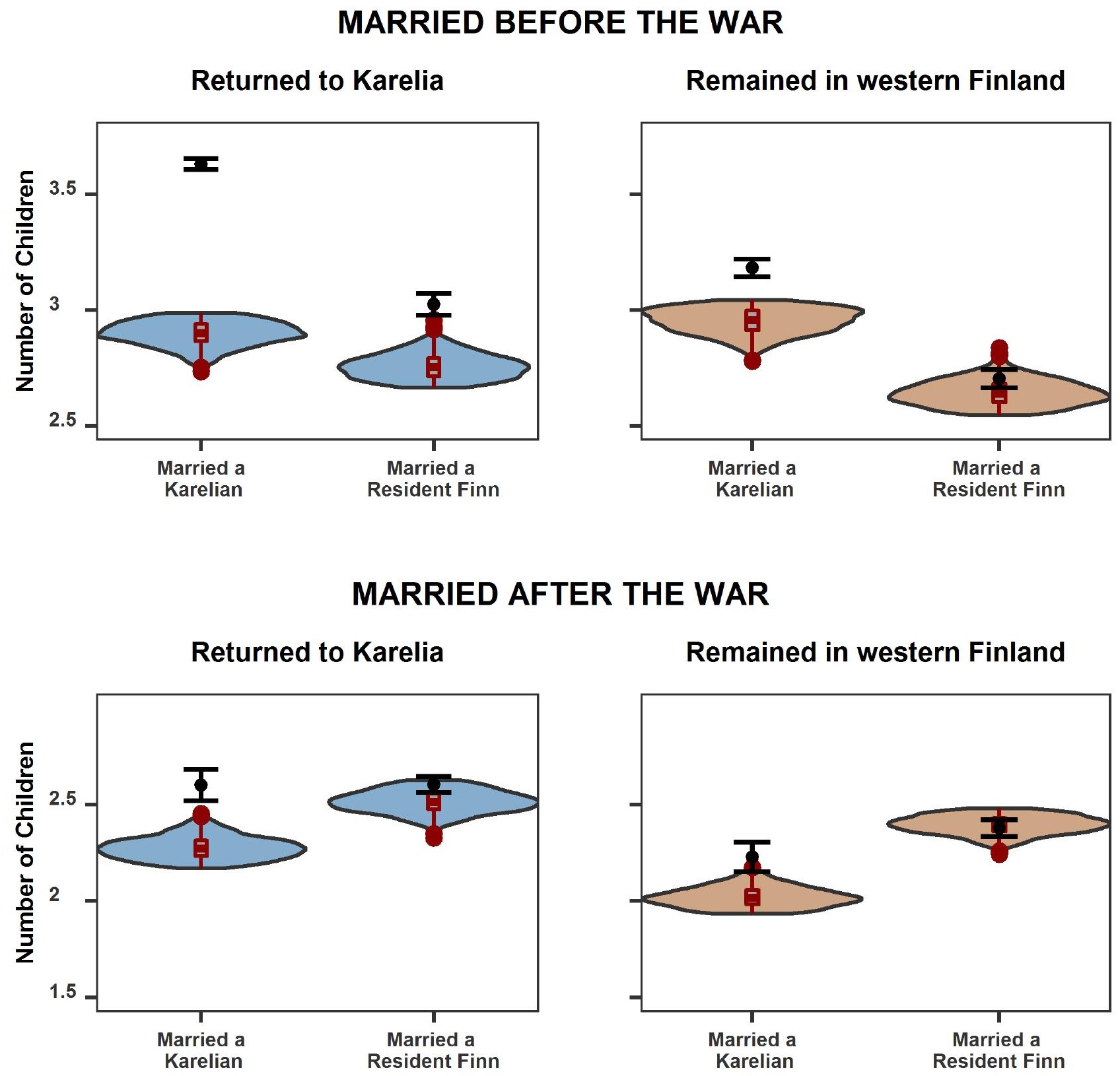

Figure 4: Reproductive costs of intermarniage are only evident before the war. Posterior distribution predictions are generated from the full model shown in the bottom panel of TableS1 ( $N=26,757)$. Before the war (top panels) evacuees who marry other Kare ians have more children (see Table S2 second panel: Intermarriage, mean $-0.11,95 \% \mathrm{Cl}-0.13$ to -0.08 ) and there are no differences between evacuees who return and evacuees who remain (see Table S2 second panel: Returned to Karelia, mean $-0.14,95 \% \mathrm{Cl}-0.18$ to 0.10 . After the war (bottom panels) evacuees who returned to Karelia have more children than those who remain in western Finland (errors bars and posterior distributions in bottom left panel are higher than bottom right panel and marrying a resi dent Finn is positively associated with higher fertility (see model results for each panel in tables S2-S4. This is particul arly true for evacuees who remain in westem Finland (bottom right pane; see al so table S4: Intermarriage, mean 0.22, $95 \% \mathrm{Cl} 0.09$ to 0.33 ) (see Table S1 for full models and Supplementary Materials Table S5 for observed data means). Model predictions (posterior distributions) can be less pronounced than differences are in the raw data (error bars) because the posterior predictions account for all of the additional variables and interactions entered into the model. The posterior distribution pl ots include the model predicted $95 \%$ highest density intervals with the lower and upper hinges of the box plots corresponding to the first and third quartiles. Error bars with points are the observed value means and standard errors. 